\title{
Alteration of oxidative stress and inflammatory cytokines induces apoptosis in diabetic nephropathy
}

\author{
JIBIN SHA $^{1,2}$, BO SUI ${ }^{1}$, XIAOQING SU ${ }^{3}$, QINGFANG MENG ${ }^{4}$ and CHENGGANG ZHANG ${ }^{2}$ \\ ${ }^{1}$ School of Sports Science and Health, Shandong Sports University, Jinan, Shandong 250102; ${ }^{2}$ Beijing Institute of \\ Radiation Medicine, Beijing 100850; ${ }^{3}$ Department of Endoscopy, Zhangqiu People's Hospital, Jinan, Shandong 250200; \\ ${ }^{4}$ School of Social Sports Science, Shandong Sports University, Jinan, Shandong 250102, P.R. China
}

Received August 4, 2016; Accepted June 21, 2017

DOI: $10.3892 / \mathrm{mmr} .2017 .7522$

\begin{abstract}
Diabetic nephropathy (DN) is one of the most significant long-term complications in terms of morbidity and mortality for diabetic patients; however, the exact cause remains unknown. To address this, the $\mathrm{DN}$ model was established, and oxidative stress indexes, including malondialdehyde (MDA), superoxide dismutase (SOD), glutathione peroxidase (GSH-Px), and inflammatory cytokines, includinginterleukin-6 (IL-6), tumor necrosis factor-alpha (TNF- $\alpha$ ) and transforming growth factor-beta (TGF- $\beta$ ), were examined by ELISA. Renal pathological alterations and cell apoptosis was examined by hematoxylin and eosin and terminal deoxynucleotidyl transferase mediated dUTP nick-end labeling staining, respectively. The expression levels of B-cell lymphoma-2 (Bcl-2), Bcl-2 associated X (Bax) and caspase-3 wereexamined by immunohistochemistry and western blotting. The DN model was correctly established, with lower body weight and the higher blood glucose in the diabetes model group. The expression levels of SOD and GSH-Px were significantly decreased in the diabetes model group; however, MDA, IL-6, TNF- $\alpha$ and TGF- $\beta$ were significantly increased. The kidney was severely damaged in the diabetes model group, with inflammatory cell invasion, increasing amount of interstitial matrix and hypertrophy with vacuolar degeneration of renal tubular cells. Cell apoptosis levels were significantly increased, and Bcl-2 was significantly decreased in the diabetes model group in contrast with that of the sham group; however, Bax and caspase-3 were significantly increased. It suggested that increased oxidative stress and inflammatory cytokines may enhance the apoptosis levels in
\end{abstract}

Correspondence to: Dr Chenggang Zhang, Beijing Institute of Radiation Medicine, 27 Taiping Road, Haidian, Beijing 100850, P.R. China

E-mail: zhangcg@bmi.ac.cn

Key words: diabetic nephropathy, streptozotocin, oxidative stress, inflammatory cytokines, apoptosis
DN, and may provide a significant diagnostic reference for $\mathrm{DN}$ in diabetes patients.

\section{Introduction}

Diabetes mellitus is, an autoimmune metabolic disorder disease with characteristics of high blood sugar over a prolonged period, and manifests as weight loss, polyuria, polydipsia and polyphagia. It is primarily classified as type I and type II diabetes based on whether the pancreas produces enough insulin or whether body cells respond appropriately to the insulin produced (1-3). Based on an epidemiological survey, all types of diabetes may combine to cause angiopathy complications, including diabetic neuropathy (4-6), diabetic encephalopathy $(7,8)$, diabetic retinopathy (9-11) and diabetic nephropathy (DN) (12-14), and is a global health problem.

DN has become a leading cause of chronic kidney disease, particularly in end-stage renal disease, and the incidence continues to rise. DN is clearly recognized as a common long-term complication of diabetes mellitus, and is characterized by nephrotic syndrome and diffuse scarring of the glomeruli $(12,15,16)$. It is frequently a symptomatic during the early stage, and kidney damage manifests after 5-10 years with symptoms of severe tiredness, headaches, a general feeling of illness, nausea, vomiting, frequent urination, lack of appetite, itchy skin and leg swelling $(17,18)$. The pathogenesis of DN has been well documented, and involves glycometabolic disorder, renal hemodynamic alterations, genetic susceptibility, activation of cytokines and oxidative stress (19-21). Slowing the progression of kidney damage and to control the associated complications of diabetes has become a core objective, and angiotensin-converting-enzyme inhibitor has been used as a treatment that reduces the proteinuria levels; however, other therapeutic strategies are required (22-24). In addition, defective apoptotic processes have been implicated in a variety of diseases. However, the involvement of apoptotic pathways in advanced stages of DN are not well understood. Therefore, the streptozotocin-induced DN model was established, and renal cell apoptosis levels were examined by immunohistochemistry (IHC) and western blotting, and suggested that apoptosis serves a significant role in the streptozotocin-induced DN 
model, and is associated with increased oxidative stress and inflammatory cytokines. Therefore, it may serve as a significant diagnostic reference in the study of DN.

\section{Materials and methods}

Experimental animals and grouping. A total of 36 specific pathogen-free Sprague Dawley rats (male, 200-220 g; age, 8-12 weeks) were purchased and raised in the Laboratory Animal Center of the Academy of Military Medical Sciences (Beijing, China) with at a temperature of $25 \pm 2^{\circ} \mathrm{C}$, humidity of $40-60 \%$ and $12 \mathrm{~h} \mathrm{light/dark} \mathrm{cycle,} \mathrm{with} \mathrm{free} \mathrm{access} \mathrm{to} \mathrm{food}$ and water, and were randomly divided into two groups: Sham $(n=18)$ and diabetes model group $(n=18)$. Rat body weight and blood glucose was examined at $0,10,20,30,40,50$ and 60 days. Furthermore, the diabetes model group was further divided into sham $(n=6), 1$ month model group $(n=6)$, and 2 month model group $(n=6)$. This experiment was approved by the Experimental Ethics Committee of the Military Medical Sciences (Beijing, China).

Establishment of rat diabeticnephropathy model by gradual streptozotocin. Prior to modeling, $1.1 \%$ (w/v) streptozotocin was prepared in citric acid buffer $(0.1 \mathrm{~mol} / \mathrm{l} ; \mathrm{pH} 4.4)$ on ice in the dark. Following $12 \mathrm{~h}$ fasting of food and water, streptozotocin $(55 \mathrm{mg} / \mathrm{kg})$ was intraperitoneally injected. For booster injection, one fifth of streptozotocin $(11 \mathrm{mg} / \mathrm{kg})$ was intraperitoneally injected at 15 days and 30 days. During modeling, rat body weight and blood glucose was examined at $0,10,20,30,40,50$ and 60 days. Subsequent to modeling, rats were anesthetized with pentobarbital sodium $(40 \mathrm{mg} / \mathrm{kg}$; Merck KGaA, Darmstadt, Germany), sacrificed by cervical dislocation and then kidney tissues were collected for further study.

Hematoxylin and eosin (HE) staining. The aforementioned kidney tissues were fixed at room temperature with $4 \%$ paraformaldehyde for at least $24 \mathrm{~h}$, and sliced (3-5 $\mu \mathrm{m})$ for staining with HE. Slides were slightly over-stained with hematoxylin for approximately 3-5 min, and any excess stain was removed with tap water. Slides were incubated for a few sec in acidic alcohol until they appeared red. Slides were then briefly rinsed in tap water to remove the acid. Bicarbonate was applied for $2 \mathrm{~min}$ until the nuclei were stained blue. The hematoxylin-stained slides were placed in 70\% ethanol after a final rinse in tap water for 3 min and were then exposed to eosin for $2 \mathrm{~min}$. Subsequently, the slides underwent three washes with $95 \%$ ethanol for $5 \mathrm{~min}$, and were transferred to absolute ethanol for clearing. Subsequent to staining, images were captured with a light microscope and analyzed using Image-Pro Plus v7.0 software (Media Cybernetics, Inc., Rockville, MD, USA) followed by histogram analysis using Origin version 9.0 software (Origin Lab, Northampton, MA, USA).

Terminal deoxynucleotidyl transferase mediated dUTP nick-end labeling method (TUNEL) staining. The aforementioned kidney tissues were fixed by $4 \%$ paraformaldehyde at room temperature for at least $24 \mathrm{~h}$, and sliced (3-5 $\mu \mathrm{m})$ prior to TUNEL staining using a TUNEL staining kit (Beijing
Zhongshan Golden Bridge Biotechnology Co., Ltd; OriGene Technologies, Inc., Beijing, China), according to the manufacturer's protocol. Slides were deparaffinized, rehydrated, washed twice with phosphate-buffered saline (PBS; $5 \mathrm{~min} /$ wash) and incubated with the kit proteinase $\mathrm{K}$ solution at $37^{\circ} \mathrm{C}$ for $20 \mathrm{~min}$. After a further two washes in PBS (5 min/wash), the slides were treated with the kit bovine serum albumin (BSA) blocking buffer at room temperature for $10 \mathrm{~min}$, followed by two washes with PBS (5 min/wash). Slides were then incubated with a $50 \mu \mathrm{l}$ TUNEL reaction mixture for $1 \mathrm{~h}$ in a humid chamber in the dark, and slides were subsequently rinsed 3 times (5 min/wash) with PBS. Then, $50 \mu 1$ streptavidin-horseradish peroxidase (HRP) solution was added to slides for $37^{\circ} \mathrm{C}$ for $30 \mathrm{~min}$, followed by three washes with PBS ( $5 \mathrm{~min} / \mathrm{wash}$ ). Finally, $100 \mu \mathrm{l}$ diaminobenzidine (DAB) solution was added for $10 \mathrm{~min}$ at room temperature, followed by three washes with PBS (5 min/wash) and hematoxylin counter staining for $3 \mathrm{~min}$ at room temperature. The sections were observed under a light microscope (Olympus Corporation, Tokyo, Japan) and five specific areas in each region were captured. Positive apoptotic cells were measured using Image-Pro Plus version 7.0 software (Media Cybernetics, Inc.). The ratio of positive apoptotic cells and total cells was calculated using Origin version 9.0 software (Origin Lab).

IHC staining. Kidney tissues were fixed and sliced as aforementioned. Endogenous peroxidase was inactivated by incubating the sections in $3 \% \mathrm{H}_{2} \mathrm{O}_{2}$ for $30 \mathrm{~min}$ at $37^{\circ} \mathrm{C}$. The sections were incubated with $10 \%$ normal goat serum (catalog no. ZKP160724-1; Suzhou Zeke Biotech Co., Ltd., Suzhou, China) in $0.01 \mathrm{M}$ PBS for $30 \mathrm{~min}$ at room temperature, and then incubated with a rabbit anti-Bcl-2 antibody (catalog no. BA0412; 1:200; Wuhan Boster Biological Technology, Ltd., Wuhan, China), rabbit anti-Bax antibody (catalog no. BA0315; 1:200; Wuhan Boster Biological Technology, Ltd.) and rabbit-anti-caspase-3 antibody (catalog no. BA3968; 1: 200; Wuhan Boster Biological Technology, Ltd.) in PBS containing $0.3 \%$ Triton X-100 overnight at $4^{\circ} \mathrm{C}$. The sections were washed three times for 5 min each with PBS and then incubated with peroxidase-conjugated goat anti-rat IgG (catalog no. ZDR-5118, 1:200; Zymed; Thermo Fisher Scientific, Inc., Waltham, MA, USA) for $1 \mathrm{~h}$ at room temperature. Finally, the sections were developed with DAB in $0.1 \mathrm{M}$ TBS containing $0.001 \% \mathrm{H}_{2} \mathrm{O}_{2}$ for $30 \mathrm{~min}$ at room temperature. The sections were observed under a light microscope (Olympus Corporation) and five specific areas in each region were captured. Integrated optical density of Bcl-2, Bax and caspase-3 positive cells were measured using Image-Pro Plus version 7.0 software (Media Cybernetics, Inc.) followed by histogram analysis using Origin version 9.0 software (Origin Lab).

Measurement of oxidative stress indexes, including malondialdehyde (MDA), superoxide dismutase (SOD) and glutathione peroxidase (GSH-Px) in rat kidneys by ELISA. A total of $20 \mu \mathrm{g}$ kidney tissue was rapidly frozen in liquid nitrogen. After thawing, tissue was homogenized and centrifuged at $13,400 \mathrm{x} g$ at $4^{\circ} \mathrm{C}$ for $15 \mathrm{~min}$, and the supernatant was collected. Subsequently, the MDA levels in the kidney were measured using a rat MDA ELISA kit (catalog no. ZKP-150051; Suzhou Zeke Biotech 
Co., Ltd.). Similarly, SOD and GSH-Px expression levels were measured with a rat SOD ELISA kit (catalog no. ZKP-150065; Suzhou Zeke Biotech Co., Ltd.), and a rat GSH-Px ELISA kit (catalog no. ZKP-150078; Suzhou Zeke Biotech Co., Ltd.), respectively, according to the manufacturer's protocol. A total of $20 \mu \mathrm{l}$ serum and $80 \mu \mathrm{l}$ sample diluent were added to the wells of a 96-well plate, gently mixed and incubated at $37^{\circ} \mathrm{C}$ for $30 \mathrm{~min}$. The plate was then washed with $100 \mu \mathrm{l}$ washing buffer 5 times for $30 \mathrm{sec}$, and then $100 \mu \mathrm{l}$ of HRP-conjugate reagent was added, except for the blank wells, and incubated at $37^{\circ} \mathrm{C}$ for $30 \mathrm{~min}$. The plate was washed with $100 \mu \mathrm{l}$ washing buffer 5 times for $30 \mathrm{sec}$, and $100 \mu \mathrm{l} \mathrm{DAB}$ substrate was added at $37^{\circ} \mathrm{C}$ for $15 \mathrm{~min}$. A total of $50 \mu \mathrm{l}$ stop solution was then added for $30 \mathrm{sec}$ at $37^{\circ} \mathrm{C}$. The absorbance was measured at a wave length of $450 \mathrm{~nm}$ using a microplate reader for $15 \mathrm{~min}$, and data was analyzed using SPSS software (version 21.0; IBM Corp., Armonk, NY, USA), and histogram analysis was performed using Origin version 9.5 software (Origin Lab).

Measurement of inflammatory cytokines, including IL-6, TNF- $\alpha$ and TGF- $\beta$ in rat kidneys by ELISA. A total of $20 \mu \mathrm{g}$ kidney tissue was rapidly frozen in liquid nitrogen, thawed, homogenized and centrifuged at $13,400 \times \mathrm{g}$ at $4^{\circ} \mathrm{C}$ for $15 \mathrm{~min}$, and the supernatant was collected. Subsequently, the IL-6 levels in the kidney sample was measured using a rat IL-6 ELISA kit (catalog no. ZKP-1598; Suzhou Zeke Biotech Co., Ltd.). Similarly, the TNF- $\alpha$ and TGF- $\beta$ expression level was also measured with a rat TNF- $\alpha$ ELISA kit (catalog no. ZKP-1500; Suzhou Zeke Biotech Co., Ltd.), and a rat TGF- $\beta$ ELISA kit (catalog no. ZKP-1500104; Suzhou Zeke Biotech Co., Ltd.), respectively, according to the manufacturer's protocol. A total of $20 \mu \mathrm{l}$ serum and $80 \mu \mathrm{l}$ sample diluent were added to the wells of a 96-well plate, gently mixed and incubated at $37^{\circ} \mathrm{C}$ for $30 \mathrm{~min}$. The plate was washed with $100 \mu \mathrm{l}$ washing buffer 5 times for $30 \mathrm{sec}$, and then $100 \mu \mathrm{l}$ HRP-conjugate reagent was added, except for blank wells, and incubated at $37^{\circ} \mathrm{C}$ for $30 \mathrm{~min}$. The plate was washed with $100 \mu \mathrm{l}$ washing buffer 5 times for $30 \mathrm{sec}$, and $100 \mu \mathrm{l} \mathrm{DAB}$ substrate was added at $37^{\circ} \mathrm{C}$ for $15 \mathrm{~min}$. A total of $50 \mu \mathrm{l}$ of stop solution was then added. Absorbance was measured at a wave length of $450 \mathrm{~nm}$ using a microplate reader for $15 \mathrm{~min}$, and analyzed using SPSS software version 21.0 (IBM Corp.), and histogram analysis was performed using Origin version 9.5 software (Origin Lab).

Western blotting. Total proteins were extracted from kidney tissues using radioimmunoprecipitation lysis buffer [50 mM Tris- $\mathrm{HCl}$ (pH 7.4), $150 \mathrm{mM} \mathrm{NaCl}, 1 \% \mathrm{NP}-40,0.1 \%$ SDS and 1\% PMSF], and quantified using a bicinchoninic acid kit (catalog no. ZKP-160814-1; Suzhou Zeke Biotech Co., Ltd.). A total of $35 \mu \mathrm{g}$ protein from kidney tissue was subjected to electrophoresis on $12 \%$ polyacrylamide gels, and transferred to a polyvinylidene difluoride membrane following the manufacturers' protocol. The membrane was blocked in 5\% skim milk at room temperature for $30 \mathrm{~min}$, and then probed with rabbit-anti-Bcl-2 antibody (catalog no. BA0412; 1:200; Wuhan Boster Biological Technology, Ltd.), rabbit-anti-Bax (catalog no. BA0315, 1:200; Wuhan Boster Biological Technology, Ltd.), and rabbit-anti-caspase-3 antibody (catalog no. BA3968, 1:200;
Table I. Body weight of sham or streptozotocin-induced DN rats.

\begin{tabular}{lcc}
\hline Time (days) & Sham $(\mathrm{g})$ & Diabetes model $(\mathrm{g})$ \\
\hline 0 & $222.65 \pm 13.81$ & $220.14 \pm 8.75$ \\
10 & $330.75 \pm 7.83$ & $269.13 \pm 11.03^{\mathrm{a}}$ \\
20 & $378.1 \pm 11.56$ & $311.45 \pm 19.42^{\mathrm{a}}$ \\
30 & $415.62 \pm 6.38$ & $325.78 \pm 23.00^{\mathrm{a}}$ \\
40 & $489.91 \pm 12.3$ & $335.45 \pm 21.03^{\mathrm{a}}$ \\
50 & $514.63 \pm 9.52$ & $342.14 \pm 31.20^{\mathrm{a}}$ \\
60 & $548.26 \pm 12.54$ & $348.26 \pm 24.12^{\mathrm{a}}$ \\
\hline
\end{tabular}

${ }^{\mathrm{a}} \mathrm{P}<0.01 \mathrm{vs}$. Sham. Data are expressed as the mean \pm standard deviation.

Wuhan Boster Biological Technology, Ltd.) for $1.5 \mathrm{~h}$ at room temperature. Subsequently, the membranes were incubated with HRP-conjugated goat anti-mouse secondary antibody (1:5,000 in TBST; OriProbe Technologies, Inc., Beijing, China) at room temperature for $1 \mathrm{~h}$. Chemiluminescence luminol reagent (catalog no. ZKP-C150044-1; Suzhou Zeke Biotech Co., Ltd.) was used to develop the immune-labeled bands on X-ray film (Suzhou Zeke Biotech Co., Ltd.), and the integrated optical density of the bands was quantified using Image J version 1.46 software (National Institutes of Health, Bethesda, MD, USA), and a histogram was generated using Origin 9.5 software (Origin Lab).

Statistical analysis. All data are expressed as the mean \pm standard deviation. Statistical analysis was performed with one-way analysis of variance and the Tukey post hoc test using SPSS software version 21.0 (IBM Corp.), and a Student's t-test was performed when comparing the means of two samples. $\mathrm{P}<0.05$ was considered to indicate a statistically significant difference.

\section{Results}

Rat body weight decreases and blood glucose significantly increases with time in the streptozotocin-induced DN model. After 60 days induction of DN with streptozotocin, compared with sham group, the body weight was significantly decreased in the diabetes model group $(\mathrm{P}<0.01$; Table I). Compared with the sham group, rats blood glucose was significantly increased to the maximum scale value $(33.33 \pm 0.00)$ after 20 days treatment with streptozotocin, and was maintained for $\geq 60$ days $(\mathrm{P}<0.01$; Table II).

The expression levels of MDA significantly increases and SOD and GSH-Px expression significantly decreases in the streptozotocin-induced DN model. The MDA expression level was significantly increased in the model group at 1 month $(2.65 \pm 0.14)$ and 2 months $(3.85 \pm 0.17)$ compared with $1.08 \pm 0.12$ in the sham group $(\mathrm{P}<0.01$; Table III). The expression level of IL- 6 , TNF- $\alpha$ and TGF- $\beta$ exhibited the same trend $(\mathrm{P}<0.01$; Table III). In addition, the expression levels of SOD and GSH-Px were significantly decreased after 1 and 2 months in the model group compared with the sham $(\mathrm{P}<0.01$; Table III). 
Table II. Blood glucose change in diabetic rats with prolonged modeling time.

\begin{tabular}{lcc}
\hline Time (days) & Sham $(\mathrm{mmol} / \mathrm{l})$ & Diabetes model $(\mathrm{mmol} / \mathrm{l})$ \\
\hline 0 & $8.35 \pm 0.04$ & $8.38 \pm 0.08$ \\
10 & $8.25 \pm 0.14$ & $30.40 \pm 2.21^{\mathrm{a}}$ \\
20 & $8.24 \pm 0.04$ & $33.33 \pm 0.00^{\mathrm{a}}$ \\
30 & $8.31 \pm 0.24$ & $33.33 \pm 0.00^{\mathrm{a}}$ \\
40 & $8.25 \pm 0.16$ & $33.33 \pm 0.00^{\mathrm{a}}$ \\
50 & $8.24 \pm 0.12$ & $33.33 \pm 0.00^{\mathrm{a}}$ \\
60 & $8.28 \pm 0.26$ & $33.33 \pm 0.00^{\mathrm{a}}$ \\
\hline
\end{tabular}

${ }^{\mathrm{a}} \mathrm{P}<0.01$ vs. Sham. Data are expressed as the mean \pm standard deviation.

Table III. MDA, SOD, GSH-Px, IL-6, TNF- $\alpha$ and TGF- $\beta$ concentrations in kidneys of sham or diabetes model rats.

\begin{tabular}{lccc}
\hline & & \multicolumn{2}{c}{ Diabetes model } \\
\cline { 3 - 4 } Group & Sham & 1 month & 2 months \\
\hline MDA (nmol/l) & $1.08 \pm 0.12$ & $2.65 \pm 0.14^{\mathrm{a}}$ & $3.85 \pm 0.17^{\mathrm{a}, \mathrm{b}}$ \\
SOD (U/1) & $74.35 \pm 2.35$ & $26.34 \pm 2.71^{\mathrm{a}}$ & $18.56 \pm 2.35^{\mathrm{a}, \mathrm{b}}$ \\
GSH-Px (U/l) & $512.25 \pm 32.15$ & $215.32 \pm 8.56^{\mathrm{a}}$ & $174.13 \pm 12.56^{\mathrm{a}, \mathrm{b}}$ \\
IL-6 (ng/l) & $21.35 \pm 5.46$ & $86.13 \pm 6.85^{\mathrm{a}}$ & $102.15 \pm 12.36^{\mathrm{a}, \mathrm{b}}$ \\
TNF- $\alpha(\mathrm{ng} / \mathrm{l})$ & $45.63 \pm 8.97$ & $125.32 \pm 11.02^{\mathrm{a}}$ & $175.34 \pm 21.03^{\mathrm{a}, \mathrm{b}}$ \\
TGF- $\beta$ (ng/l) & $31.52 \pm 4.75$ & $105.46 \pm 15.54^{\mathrm{a}}$ & $159.93 \pm 12.86^{\mathrm{a}, \mathrm{b}}$ \\
\hline
\end{tabular}

${ }^{a} \mathrm{P}<0.01$ vs. Sham; ${ }^{\mathrm{b}} \mathrm{P}<0.01$ vs. 1 month Diabetes model. Data are expressed as the mean \pm standard deviation. MDA, malondialdehyde; SOD, superoxide dismutase; GSH-Px, glutathione peroxidase; IL-6, interleukin 6 ; TNF- $\alpha$, tumor necrosis factor- $\alpha$; TGF- $\beta$, transforming growth factor- $\beta$.

Kidney tissue morphology is loosely packed and severely damaged in the diabetes model group. As demonstrated by HE staining, in the sham group, the kidney cells were tightly distributed, with regular acinus, no hyperchromatic nuclei and no inflammatory cell invasion. However, in the model group, the kidney tissue appeared to be loosely packed and severely damaged, the cell nuclei hyperchromatic, with severe inflammation, an increased amount of interstitial matrix and hypertrophy with vacuolar degeneration of renal tubular cells; the DN model further aggravated these effects over time, as the level of damage increased following 2 months when compared to 1 month post-model induction (Fig. 1).

Renal cell apoptosis level and apoptosis ratio significantly increases with time in the streptozotocin-induced DN model group. After treatment with streptozotocin, renal cell apoptosis and the apoptotic ratio was significantly increased in the 1 and 2 month model groups when compared with the sham group $(\mathrm{P}<0.01$; Fig. 2$)$. The increase was greater in the 2 months model group compared with the 1 month model group $(\mathrm{P}<0.01$; Fig. 2$)$.
The expression levels of Bax and caspase-3 significantly increase and of Bcl-2 significantly decrease in the streptozotocin-induced DN model group. Following treatment with streptozotocin, Bax protein expression levels were significantly increased in the 1 and 2 month model groups compared with the sham group $(\mathrm{P}<0.01$, Fig. 3$)$ and the increase was greater in the 2 month model group compared with the 1 month model group ( $\mathrm{P}<0.01$; Fig. 3). Bcl-2 protein expression levels were significantly decreased in 1 month model group and 2 months model group when compared to that of sham ( $\mathrm{P}<0.01$; Fig. 4). Caspase-3 protein expression levels were also significantly increased in the diabetes model group compared with the sham group $(\mathrm{P}<0.01$; Fig. 5). Western blotting also confirmed these observations (Fig. 6).

\section{Discussion}

The present study demonstrated that the streptozotocin-induced DN model was established in rats, and these rats exhibited reduced body weight and higher blood glucose levels compared with sham rats. Diabetic model rats additionally had lower expression levels of SOD and GSH-Px, and the higher expression of MDA, IL-6, TNF- $\alpha$ and TGF- $\beta$ in their kidneys than that of sham group rats. Additionally, renal cells were loosely packed and severely damaged, and apoptosis was significantly increased with time in diabetic rats. The expression levels of Bax and caspase- 3 were increased, and expression of Bcl-2 was decreased in diabetic rats. Streptozotocin may increase or decrease the oxidative stress index and inflammatory cytokines to further enhance apoptosis in DN.

Streptozotocin is a natural glucosamine nitrosourea compound, and was originally identified as an antibiotic in 1959 by Vavra et al (25), and may induce DNA damage of $\beta$ cells of the pancreas islets in mammals (26-28). When pancreas islets cells were damaged by streptozotocin, blood glucose levels were regulated by production of the hormone insulin $(14,16)$. In the present study, the blood glucose of rats in the diabetes model group was rapidly increased at 20 days, and was steadily maintained for $\geq 60$ days. In addition, diabetic symptoms of hyperphagia, hyperposia and hyperuresis appeared at 3 days and this was followed by slow movements, emaciation, hypomotility and withered fur (data not shown). Pathological features of the kidney included loosely packed cells, severe inflammatory cell invasion, increasing amounts of interstitial matrix and hypertrophy with vacuolar degeneration of renal tubular cells. Apoptosis is a form of programmed cell death that is characterized by cell shrinkage, chromatin condensation and DNA fragmentation. TUNEL staining demonstrated that renal apoptosis was significantly increased in the diabetes model group.

DN causes a number of alterations to metabolism and blood circulation, and large amounts of reactive oxygen species (ROS) and inflammatory molecules are produced (29-31). MDA is a terminal product of lipid peroxide and its expression levels may indirectly reflect the degree of cell damage (32). SOD and GSH-Px are free radical scavenging enzyme system members which serve an important role in oxidative stress and anti-oxidative stress (29-31). IL-6 is an inflammatory cytokine that acts as 


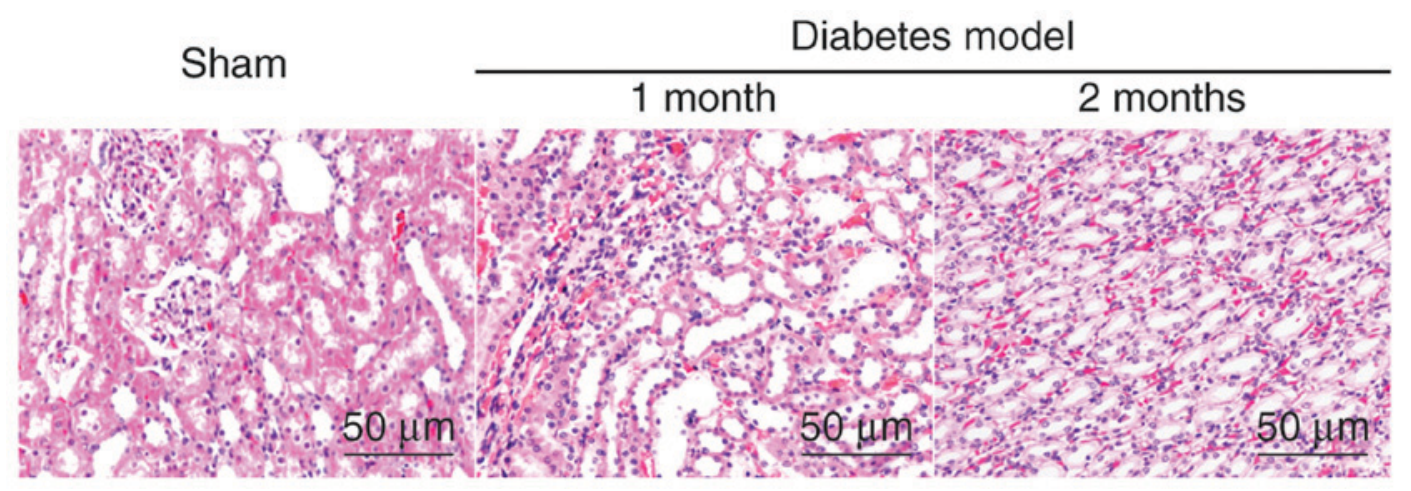

Figure 1. Morphological alterations in kidney tissue by hematoxylin and eosin staining. The images suggested that the morphological structure of renal tissues from diabetes model rats was loose and severely damaged, as increased cell nuclei staining was observed. Thickening of the glomerular basement membrane and the widening of mesangium was also observed.
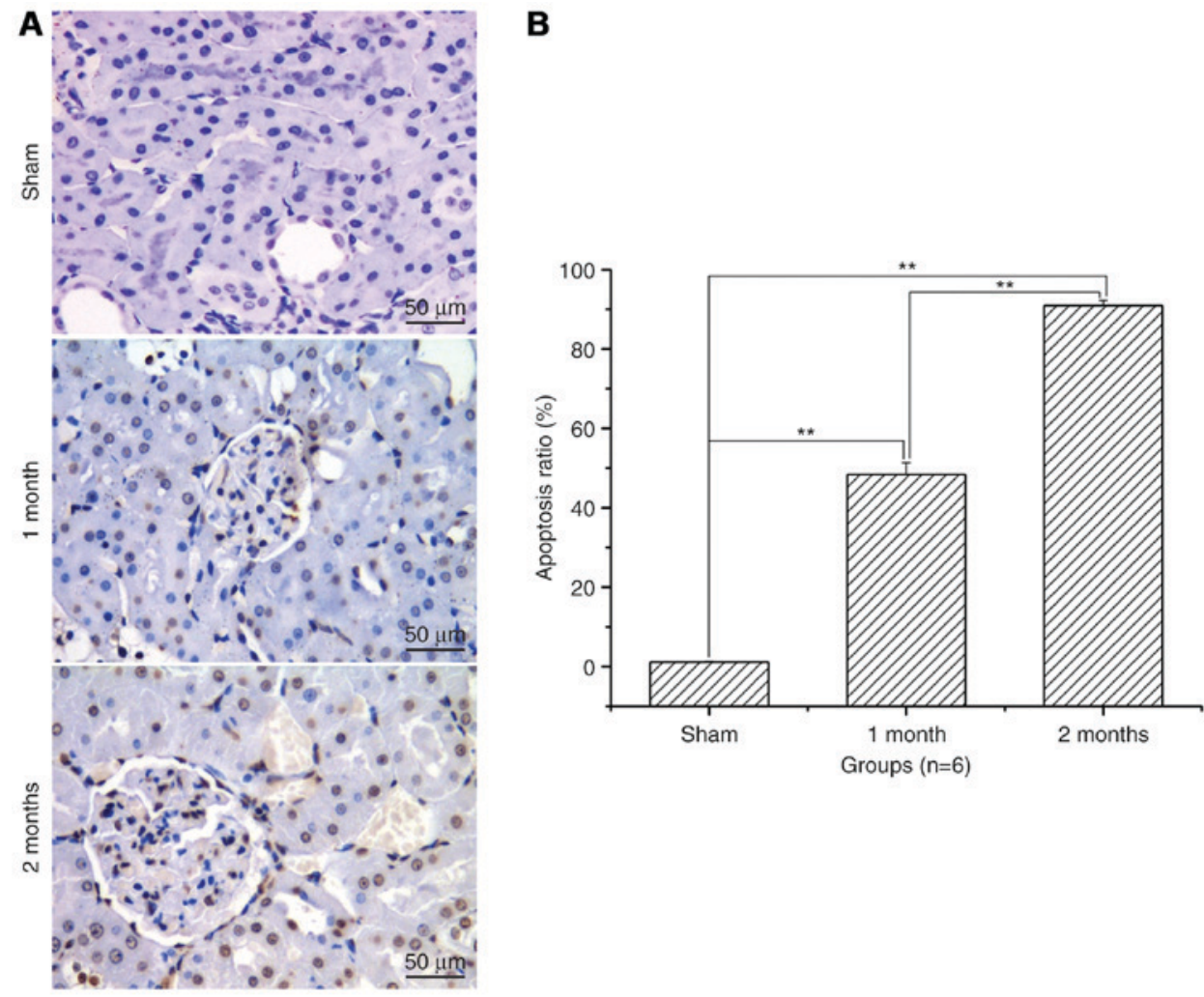

Figure 2. Renal cell apoptosis levels via TUNEL staining. (A) Renal cell apoptosis by TUNEL staining. (B) Histogram analysis. The images indicated that renal cell apoptosis levels and the apoptosis ratio were significantly increased after induction of diabetic nephropathy with streptozotocin. Data are expressed as the mean \pm standard deviation. ${ }^{* *} \mathrm{P}<0.01$. TUNEL, terminal deoxynucleotidyl transferase mediated dUTP nick-end labeling.

both a pro-inflammatory cytokine and an anti-inflammatory cytokine during an immune response $(33,34)$. TNF- $\alpha$ is a cell signaling cytokine involved in systemic inflammation and serves a role in the regulation of immune cells $(35,36)$. TGF- $\beta$ is a pleiotropic cytokine that serves fundamental roles in the development and physiology of diverse animal species (35). To elucidate these indexes in streptozotocin-induced DN model, the concentrations of MDA, SOD, GSH-Px, IL-6, TNF- $\alpha$ and TGF- $\beta$ was measured by ELISA. Higher concentrations of MDA, IL-6, TNF- $\alpha$ and TGF- $\beta$, and lower concentrations of SOD and GSH-Px, were detected in the diabetes model group. Results also suggested that abnormal metabolism and apoptosis of renal cells in DN was more apparent at 2 months than at 1 month induction with streptozotocin.

Apoptosis is a process of programmed cell death that occurs in multicellular organisms. In addition to its importance as a biological phenomenon, defective apoptotic processes have been implicated in a variety of diseases $(37,38)$. Factors including Fas receptors and caspases promote apoptosis, whereas certain members of the Bcl-2 family of proteins inhibit apoptosis $(39,40)$. Bcl-2 is considered to be an important anti-apoptotic protein whereas Bax acts as a pro-apoptotic regulator (41). Caspase-3 serves a central role in the transduction of endoplasmic reticulum apoptotic signals $(42,43)$. Having demonstrated that apoptosis contributes to the 


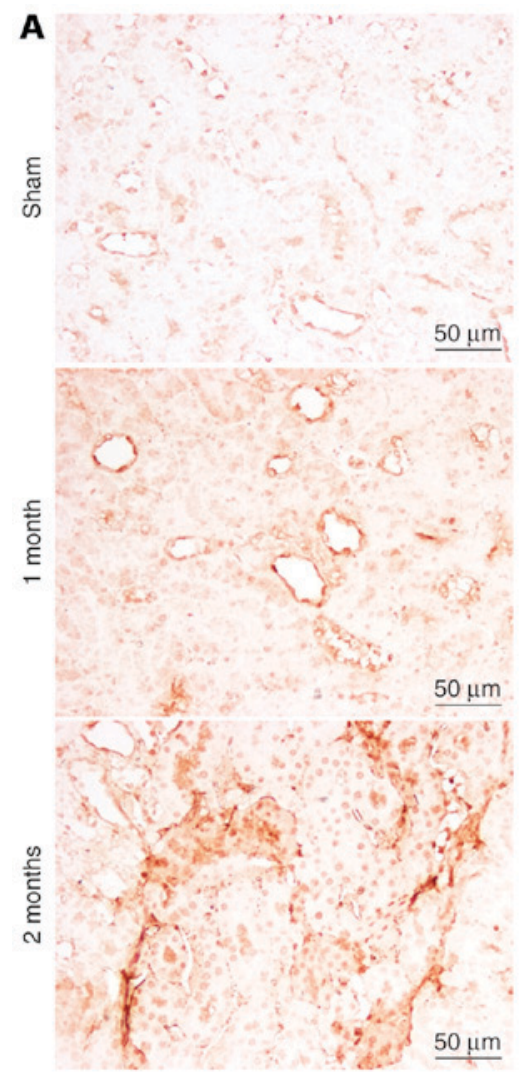

\section{B}

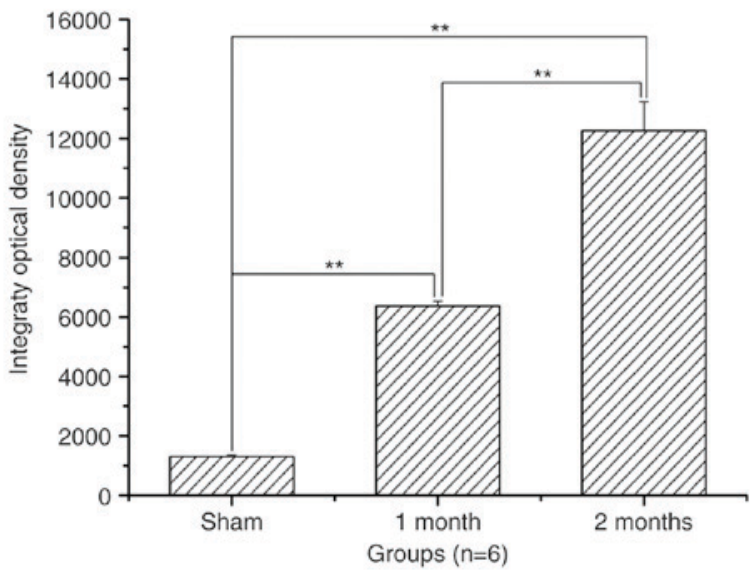

Figure 3. Bax protein expression levels via immunohistochemical staining. (A) Bax protein expression levels in kidney tissues from the sham, 1 or 2 month diabetic rats. (B) Histogram analysis. Bax expression levels were significantly increased following induction of diabetic nephropathy with streptozotocin. Data are expressed as the mean \pm standard deviation. ${ }^{* *} \mathrm{P}<0.01$. Bax, Bcl-2 associated $\mathrm{X}$.

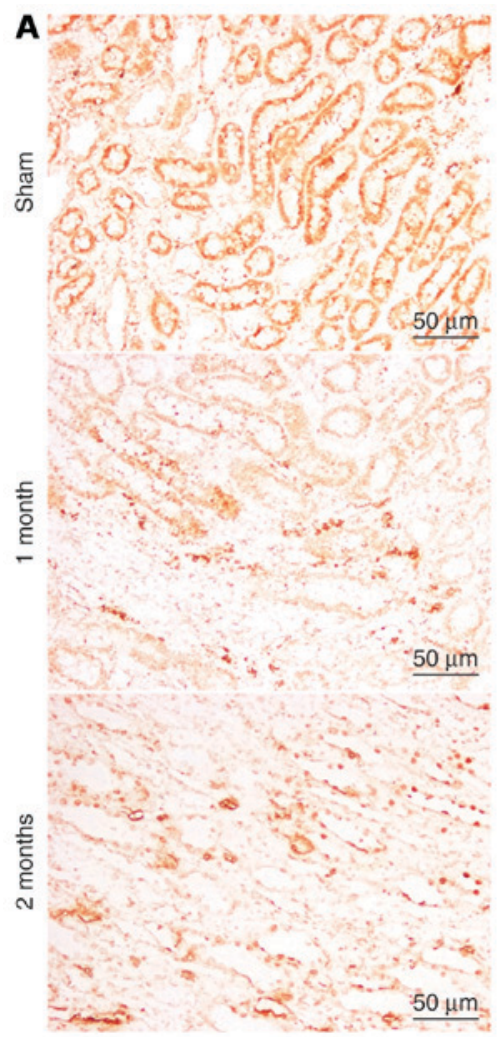

\section{B}

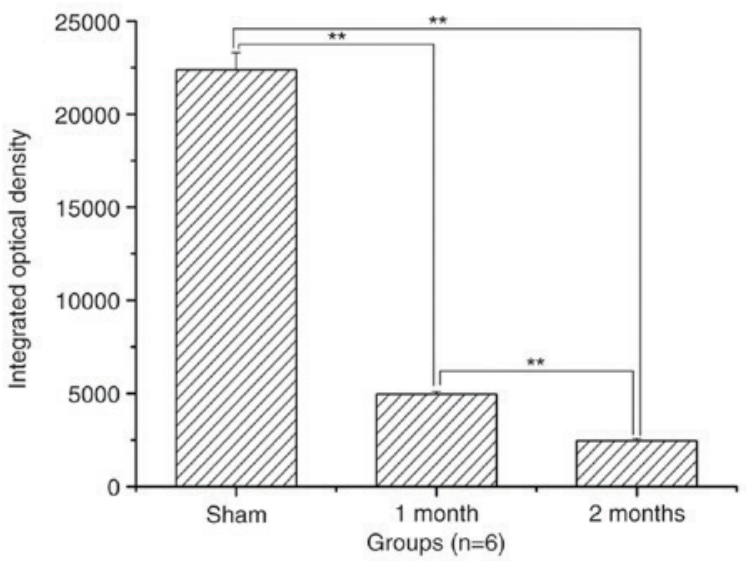

Figure 4. Bcl-2 protein expression levels via immunohistochemical staining. (A) Bcl-2 protein expression levels in kidney tissues from the sham, 1 or 2 month diabetic rats. (B) Histogram analysis. Bcl-2 expression levels were significantly decreased after induction of diabetic nephropathy with streptozotocin. Data are expressed as the mean \pm standard deviation. ${ }^{* *} \mathrm{P}<0.01$. Bcl-2, B-cell lymphoma-2. 


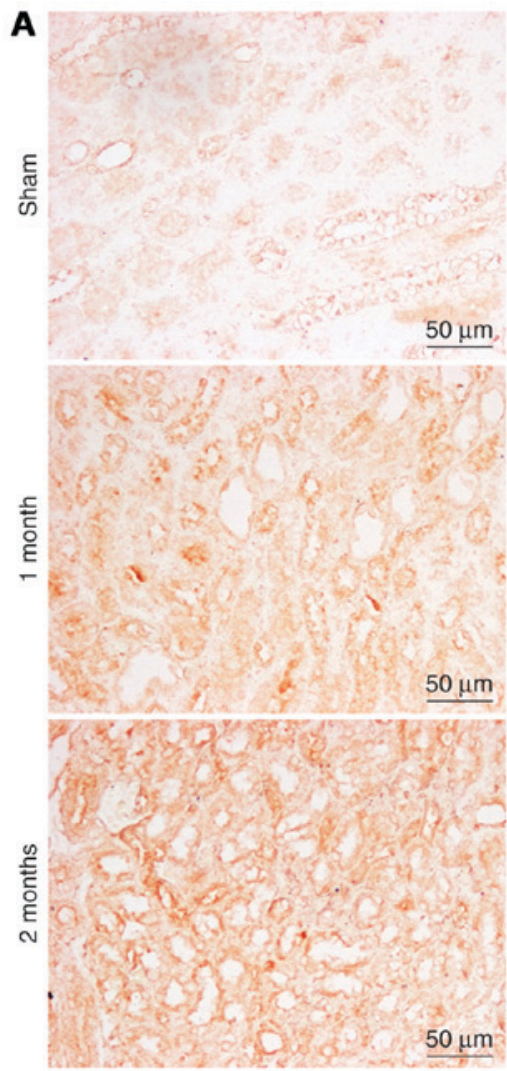

B

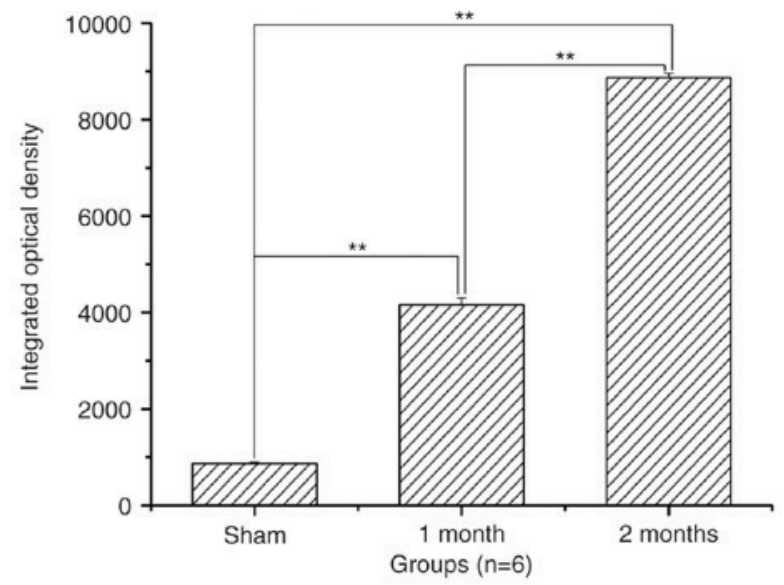

Figure 5. Caspase-3 protein expression levels assay via immunohistochemical staining. (A) Caspase-3 protein expression levels in kidney tissues from the sham, 1 or 2 month diabetic rats. (B) Histogram analysis. Caspase-3 expression levels were significantly increased after induction of diabetic nephropathy with streptozotocin. Data are expressed as the mean \pm standard deviation. ${ }^{* *} \mathrm{P}<0.01$.

A

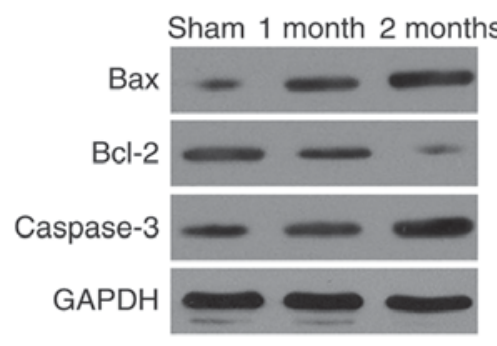

B

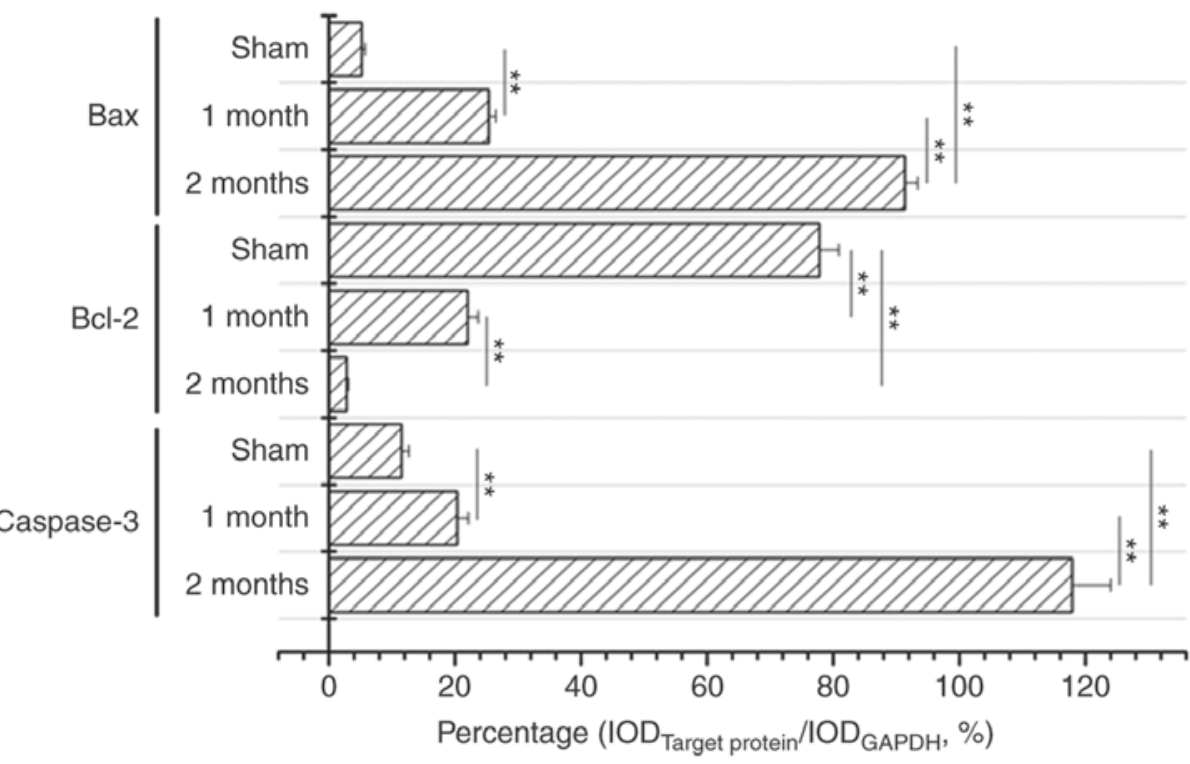

Figure 6. Expression levels of Bax, Bcl-2and caspase-3by western blotting. (A) Western blot assay of Bax, Bcl-2and caspase-3 in kidney tissues from the sham, 1 or 2 month diabetic rats. (B) Histogram analysis. The expression levels of Bax and caspase-3 were significantly increased; however, Bcl-2 was significantly decreased after induction of diabetic nephropathy with streptozotocin. Data are expressed as the mean \pm standard deviation. ${ }^{* *} \mathrm{P}<0.01$. Bax, Bcl-2 associated $\mathrm{X}$; Bcl-2, B-cell lymphoma-2; IOD, integrated optical density.

development of DN, apoptosis proteins were further investigated, including Bcl-2, Bax and caspase-3. Expression of Bax and caspase- 3 was increased with prolonged streptozotocin induction; however, Bcl-2 was decreased, which suggested that apoptosis contributed to the development of DN in rats. Due to the limited amount of funding and available drug interventions, only certain therapies that reduce cell apoptosis are studied in DN. 
In conclusion, streptozotocin induced DN in rats and induced a change in morphological structure, oxidative stress indexes, inflammatory cytokines and apoptosis. Apoptosis may contribute to the development of $\mathrm{DN}$ in rats.

\section{Acknowledgements}

The present study was sponsored by the Natural Science Foundation of Shandong Province (grant no. ZR2014JL024) and the Project of Shandong Province Higher Educational Science and Technology Program (grant no. J13LE04).

\section{References}

1. Zhang Y, Liu T, Chen Y, Dong Z, Zhang J, Sun Y, Jin B, Gao F, Guo S and Zhuang R: CD226 reduces endothelial cell glucose uptake under hyperglycemic conditions with inflammation in type 2 diabetes mellitus. Oncotarget 7: 12010-12023, 2016.

2. Song SO, Song YD, Nam JY, Park KH, Yoon JH, Son KM, Ko Y and Lim DH: Epidemiology of type 1 diabetes mellitus in Korea through an investigation of the national registration project of type 1 diabetes for the reimbursement of glucometer strips with additional analyses using claims data. Diabetes Metab J 40 : 35-45, 2016

3. Bhatt AB, Mulvey CK, Qasim AN, Nair JV, Rickels MR, Prenner SB, Iqbal N and Reilly MP: Selective association of electrocardiographic abnormalities with insulin sensitivity and beta-cell function in type 2 diabetes mellitus: A cross sectional analysis. Diabetes Metab Res Rev 32: 736-744, 2016.

4. Zhou J, Du X, Long M, Zhang Z, Zhou S and Qian G: Neuroprotective effect of berberine is mediated by MAPK signaling pathway in experimental diabetic neuropathy in rats. Eur J Pharmacol 774: 87-94, 2016.

5. Tesfaye S, Selvarajah D, Gandhi R, Greig M, Shillo P, Fang F and Wilkinson ID: Diabetic peripheral neuropathy may not be as its name suggests: Evidence from magnetic resonance imaging. Pain 157 (Suppl 1): S72-S80, 2016.

6. Erbaş O, Oltulu F, Yilmaz M, Yavaşoğlu A and Taşkıran D: Neuroprotective effects of chronic administration of levetiracetam in a rat model of diabetic neuropathy. Diabetes Res Clin Pract 114: 106-116, 2016.

7. Motawi TK, Darwish HA, Hamed MA, El-Rigal NS and Naser AFA: A therapeutic insight of niacin and coenzyme Q10 against diabetic encephalopathy in rats. Mol Neurobiol 54: 1601-1611, 2017.

8. Cai XJ, Xu HQ and Lu Y: C-peptide and diabetic encephalopathy. Chin Med Sci J 26: 119-125, 2011.

9. Wang YY, Zhang D, Jiang ZY, Lu XQ, Zheng X, Yu YJ, Wang YG and Dong J: Positive association between betatrophin and diabetic retinopathy risk in type 2 diabetes patients. Horm Metab Res 48: 169-173, 2016.

10. Micheletti JM, Hendrick AM, Khan FN, Ziemer DC and Pasquel FJ: Current and next generation portable screening devices for diabetic retinopathy. J Diabetes Sci Technol 10: 295-300, 2016.

11. Ebrahimi MH and Gharibi H: A case study of a patient with diabetic retinopathy. Diabetes Metab Syndr 10: 166-168, 2016.

12. Zheng Z and Zheng F: Immune cells and inflammation in diabetic nephropathy. J Diabetes Res 2016: 1841690, 2016.

13. Skov J, Christiansen JS and Poulsen PL: Hypertension and diabetic nephropathy. Endocr Dev 31: 97-107, 2016.

14. Lytvyn Y, Bjornstad P, Pun N and Cherney DZ: New and old agents in the management of diabetic nephropathy. Curr Opin Nephrol Hypertens 25: 232-239, 2016.

15. Zheng S, Powell DW, Zheng F, Kantharidis P and Gnudi L: Diabetic nephropathy: Proteinuria, inflammation, and fibrosis. J Diabetes Res 2016: 5241549, 2016.

16. Wanchoo R and Jhaveri KD: Nephrology crosswords: Diabetic nephropathy. Kidney Int 88: 647-648, 2015.

17. Chan GC and Tang SC: Diabetic nephropathy: Landmark clinical trials and tribulations. Nephrol Dial Transplant 31: 359-368, 2016.

18. Zhang Y, Yang J, Zheng M, Wang Y, Ren H, Xu Y, Yang Y, Cheng J, Han F, Yang X, et al: Clinical characteristics and predictive factors of subclinical diabetic nephropathy. Exp Clin Endocrinol Diabetes 123: 132-138, 2015.
19. Barchetta I, Guglielmi C, Bertoccini L, Calella D, Manfrini S, Secchi C, Pozzilli P and Cavallo MG; IMDIAB group: Therapy with proton pump inhibitors in patients with type 2 diabetes is independently associated with improved glycometabolic control. Acta Diabetol 52: 873-880, 2015.

20. Bhat KG and Periasamy PK: Effect of long-term transfusion therapy on the glycometabolic status and pancreatic Beta cell function in patients with Beta thalassemia major. J Family Med Prim Care 3: 119-123, 2014

21. Chen B, Niu YW, Xie T, Miao MY, Tian M, Ji XY, Qing C and Lu SL: Relationship between cutaneous glycometabolic disorders and cutaneous neuropathy in diabetic rats. Zhonghua Shao Shang Za Zhi 27: 139-144, 2011 (In Chinese).

22. Tian ML, Shen Y, Sun ZL and Zha Y: Efficacy and safety of combining pentoxifylline with angiotensin-converting enzyme inhibitor or angiotensin II receptor blocker in diabetic nephropathy: A meta-analysis. Int Urol Nephrol 47: 815-822, 2015.

23. Patil MR, Mishra A, Jain N, Gutch M and Tewari R: Weight loss for reduction of proteinuria in diabetic nephropathy: Comparison with angiotensin-converting enzyme inhibitor therapy. Indian J Nephrol 23: 108-113, 2013.

24. Abu-Romeh SH, Nawaz MK, Ali JH, Al-Suhaili AR and Abu-Jayyab AK: Short-term effect of angiotensin-converting enzyme inhibitor enalapril in incipient diabetic nephropathy. Clin Nephrol 31: 18-21, 1989.

25. Vavra JJ, Deboer C, Dietz A, Hanka LJ and Sokolski WT: Streptozotocin, a new antibacterial antibiotic. Antibiot Annu 7: 230-235, 1959.

26. Zhu D, Zhang L, Cheng L, Ren L, Tang J and Sun D: Pancreatic kininogenase ameliorates renal fibrosis in streptozotocin induced-diabetic nephropathy rat. Kidney Blood Press Res 41: 9-17, 2016.

27. Zhang Y, Hu T, Zhou H, Jin G and Yang Y: Antidiabetic effect of polysaccharides from Pleurotus ostreatus in streptozotocin-induced diabetic rats. Int J Biol Macromol 83: 126-132, 2016.

28. Yeh PT, Huang HW, Yang CM, Yang WS and Yang CH: Astaxanthin inhibits expression of retinal oxidative stress and inflammatory mediators in streptozotocin-induced diabetic rats. PLoS One 11: e0146438, 2016.

29. Lindblom R, Higgins G, Coughlan M and de Haan JB: Targeting mitochondria and reactive oxygen species-driven pathogenesis in diabetic nephropathy. Rev Diabet Stud 12: 134-156, 2015.

30. Nishikawa T, Brownlee M and Araki E: Mitochondrial reactive oxygen species in the pathogenesis of early diabetic nephropathy. J Diabetes Investig 6: 137-139, 2015.

31. Ha H, Hwang IA, Park JH and Lee HB: Role of reactive oxygen species in the pathogenesis of diabetic nephropathy. Diabetes Res Clin Pract 82 (Suppl 1): S42-S45, 2008.

32. Utsumi K, Yasuda F, Watanabe Y, Higo S, Hirama A, Fujita E, Ueda K, Mii A, Kaneko T, Mishina M, et al: Effects of olmesartan and imidapril on the plasma adiponectin, P-selectin, and MDA-LDL levels of diabetic nephropathy patients. Clin Chim Acta 413: 348-349, 2012.

33. Rakitianskaia IA, Riabov SI, Dubrova AG, Azanchevskaia SV, Riabova TS and Gurkov AS: The role of IL-6 in the development of morphological changes in renal tissue in elderly patients with type 2 diabetes complicated by diabetic nephropathy. Adv Gerontol 25: 632-637, 2012 (In Russian).

34. Svensson MK and Eriksson JW: Change in the amount of body fat and IL-6 levels is related to altered insulin sensitivity in type 1 diabetes patients with or without diabetic nephropathy. Horm Metab Res 43: 209-215, 2011.

35. Guclu A, Erken HA, Erken G, Dodurga Y, Yay A, Özçoban Ö, Şimşek H, Akçılar A and Koçak FE: The effects of ozone therapy on caspase pathways, TNF- $\alpha$, and HIF-1 $\alpha$ in diabetic nephropathy. Int Urol Nephrol 48: 441-450, 2016.

36. Navarro JF and Mora-Fernández C: The role of TNF-alpha in diabetic nephropathy: Pathogenic and therapeutic implications. Cytokine Growth Factor Rev 17: 441-450, 2006.

37. Elsherbiny NM, Al-Gayyar MM and Abd El Galil KH: Nephroprotective role of dipyridamole in diabetic nephropathy: Effect on inflammation and apoptosis. Life Sci 143: 8-17, 2015.

38. Susztak K, Raff AC, Schiffer $M$ and Böttinger EP: Glucose-induced reactive oxygen species cause apoptosis of podocytes and podocyte depletion at the onset of diabetic nephropathy. Diabetes 55: 225-233, 2006. 
39. Ghule AE, Jadhav SS and Bodhankar SL: Trigonelline ameliorates diabetic hypertensive nephropathy by suppression of oxidative stress in kidney and reduction in renal cell apoptosis and fibrosis in streptozotocin induced neonatal diabetic (nSTZ) rats. Int Immunopharmacol 14: 740-748, 2012.

40. Baba K, Minatoguchi S, Sano H, Kagawa T, Murata I, Takemura G, Hirano T, Ohashi H, Takemura M, Fujiwara T and Fujiwara H: Involvement of apoptosis in patients with diabetic nephropathy: A study on plasma soluble Fas levels and pathological findings. Nephrology (Carlton) 9: 94-99, 2004.
41. Borkan SC: The role of BCL-2 family members in acute kidney injury. Semin Nephrol 36: 237-250, 2016.

42. Kuribayashi K, Mayes PA and El-Deiry WS: What are caspases 3 and 7 doing upstream of the mitochondria? Cancer Biol Ther 5: 763-765, 2006

43. Lakhani SA, Masud A, Kuida K, Porter GA Jr, Booth CJ, Mehal WZ, Inayat I and Flavell RA: Caspases 3 and 7: Key mediators of mitochondrial events of apoptosis. Science 311: $847-851,2006$ 